\title{
BMJ Open Father involvement in early child- rearing and behavioural outcomes in their pre-adolescent children: evidence from the ALSPAC UK birth cohort
}

\author{
Charles Opondo, Maggie Redshaw, Emily Savage-McGlynn, Maria A Quigley
}

To cite: Opondo C, Redshaw M, SavageMcGlynn E, et al. Father involvement in early childrearing and behavioural outcomes in their pre-adolescent children: evidence from the ALSPAC UK birth cohort. BMJ Open 2016;6: 012034. doi:10.1136/bmjopen-2016012034

- Prepublication history for this paper is available online. To view these files please visit the journal online (http://dx.doi.org/10.1136/ bmjopen-2016-012034).

Received 24 March 2016 Revised 21 June 2016 Accepted 2 August 2016

CrossMark

Policy Research Unit in Maternal Health and Care, National Perinatal Epidemiology Unit, Nuffield Department of Population Health, University of Oxford, Oxford, UK

Correspondence to Dr Charles Opondo; charles. opondo@npeu.ox.ac.uk

\section{ABSTRACT}

Objective: To explore the nature of paternal involvement in early child-rearing adopting a social developmental perspective, and estimate its effect on behavioural outcomes of children aged 9 and 11 years.

Setting: The data come from the Avon Longitudinal Study of Parents and Children (ALSPAC) cohort recruited in the former county of Avon in the southwest of England.

Participants: Out of the 14701 children in this cohort who were alive at 1 year, 10440 children were living with both parents at 8 months and were therefore eligible. Outcome data were available for 6898 children at 9 years and 6328 children at 11 years.

Main exposure: Paternal involvement was measured using factor scores obtained through factor analysis of fathers' responses on their participation in, understanding of, and feelings about their child's early upbringing.

Outcome: Behavioural problems were measured using the Strengths and Difficulties Questionnaire (SDQ) total difficulties score.

Results: 3 factors were identified in the factor analysis: Factor 1 described fathers' emotional response to the child; factor 2 measured the frequency of fathers' involvement in domestic and childcare activities; factor 3 characterised fathers' feelings of security in their role as parent and partner. Children of fathers with high scores on factors 1 and 3 had $14 \%$ (OR $0.86,95 \% \mathrm{Cl} 0.79$ to $0.94, \mathrm{p}=0.001$ ) and $13 \%$ (OR $0.87,95 \% \mathrm{Cl} 0.79$ to $0.96, p=0.006$ ), respectively, lower adjusted odds of behavioural problems at 9 years. Factors 1 and 3 were associated with comparable reduction in adjusted odds of behavioural problems at 11 years $(0 \mathrm{R} 0.89,95 \% \mathrm{Cl} 0.81$ to 0.98 , $\mathrm{p}=0.017$ and $\mathrm{OR} 0.89,95 \% \mathrm{Cl} 0.81$ to $0.99, \mathrm{p}=0.034$, respectively). Factor 2 was not associated with the outcome.

Conclusions: Psychological and emotional aspects of paternal involvement in children's early upbringing, particularly how new fathers see themselves as parents and adjust to the role, rather than the quantity of direct involvement in childcare, is associated with positive behavioural outcomes in children.

\section{Strengths and limitations of this study}

- The study is based on a large sample derived from detailed cohort data.

- A rigorous approach has been adopted to explore the multifaceted nature of the main exposure.

- The study highlights the role of fathers in child development, which has been relatively under-researched.

- Findings are based on observational data which is often subject to unmeasured confounding.

- The main exposure and outcome are based on self-report, which may be subject to bias.

\section{INTRODUCTION}

In most societies, the involvement of fathers in child-rearing has traditionally been framed as the role of 'provider', ${ }^{2}{ }^{2}$ with mothers doing most of the task-oriented caring and nurturing of children. However, in recent decades social changes including the rapid increase in the proportion of working mothers $^{3-5}$ and changes in employment regulations such as increased paternity leave have resulted in a shift towards more of the direct parenting duties being shared by both parents. ${ }^{6}$ Understanding the nature and effect of fathers' involvement on the health and well-being of children could therefore help inform policies aimed at improving family psychological and health outcomes.

The nature of parenting in a child's early years is thought to play an important role in influencing the child's immediate and longterm well-being and mental health, including social development, ${ }^{7} 8$ and cognitive and educational outcomes. ${ }^{9}$ The years of middle childhood preceding adolescence represent a developmental stage that is marked by rapid physical growth, cognitive change and the development of social awareness and 
skills. ${ }^{10}$ The nature and extent of fathers' involvement in parenting may change over the course of a child's life. However, early paternal involvement is often associated with continuing engagement and may be a proxy measure of overall engagement. ${ }^{11-13}$ Early parenting can also affect outcomes later in life. ${ }^{14}{ }^{15}$ For these reasons we were interested in whether fathers' involvement early in their child's life was associated with the child's later mental health and social development. We focused on the child's behaviour as a component of mental health because of its strong link with cognitive ${ }^{16}$ and educational outcomes. ${ }^{17}$

Paternal involvement, as with maternal involvement and that of the family more broadly, is multifaceted. ${ }^{18} 19$ It can be characterised by: fathers' accessibility to their children measured by their frequency of contact with the child, ${ }^{20}{ }^{21}$ co-residence with the child ${ }^{20}$ or even presence at the child's birth; ${ }^{22}$ their engagement in childcare activities such as playing, feeding and bathing; ${ }^{23-25}$ and their demonstration of responsibility in providing for the material $^{25}$ and emotional ${ }^{26}$ needs of their children. Nevertheless, many studies have tended to characterise paternal involvement as a unidimensional construct. ${ }^{27}$ The failure to adopt a more multidimensional approach may explain why the evidence for its effect on mental health outcomes in children is unclear.

In this study we sought to first identify the multidimensional aspects of paternal involvement before investigating their potential influence on pre-adolescent children's behaviour. We then explored the relationship between paternal involvement in the child's upbringing at 8 weeks and 8 months postnatally and child behavioural outcomes at age 9 and 11 years, hypothesising that greater early paternal involvement would be associated with positive behavioural outcomes.

\section{METHODS}

\section{Data}

Data were drawn from the Avon Longitudinal Study of Parents and Children (ALSPAC) cohort. $^{28}{ }^{29}$ It is based on a sample of children born to mothers living in the former county of Avon in the southwest of England between April 1991 and December 1992. A detailed description of the sample profile has been provided elsewhere $^{3031}$ and the study website contains details of all the data that is available through a fully searchable data dictionary. ${ }^{32}$

There were 14701 children in the total sample who were alive at 1 year. Data on 14688 term singletons and twins who were alive at age 1 year were provided for these analyses and 13 observations on higher-order multiple births omitted from our data to preserve confidentiality. We also excluded 713 children recruited retrospectively when the children in the original core sample were around 7 years old (phase II and phase III recruitment) and 3535 children whose mothers did not live with (or report living with) a partner at 8 months. Out of the remaining 10440 eligible children, the analysis was based on 6898 and 6328 children whose mothers completed the Strengths and Difficulties Questionnaire (SDQ) at age 9 and 11 years, respectively (figure 1).

\section{Outcome, exposure and potential confounder variables}

Data were collected using self-completion questionnaires sent to mothers and their partners after recruitment and when the child was aged 8 weeks, 8 months, 9 years and 11 years. The questionnaires asked about mental health, parenting and childcare, behaviour, socioeconomic status (SES) of parents, and child development.

The outcome was the child's behaviour measured by SDQ completed by the mother. ${ }^{33}$ This tool has five subscales, namely 'emotional symptoms', 'conduct problems', 'hyperactivity', 'peer relationship problems' and 'prosocial behaviour'. Each scale is made up of five items giving a total of 25 items. The items are statements about psychological attributes, some positive (eg, 'considerate of other people's feelings' and 'kind to younger children') and others negative (eg, 'restless, overactive, cannot stay still for long' and 'nervous or clingy in new situations, easily loses confidence'). One of three ordered responses are given to each question: 0 ('not true'), 1 ('somewhat true') or 2 ('certainly true'). These are then summed up to obtain the scale scores and the total SDQ score. In our analyses we used the SDQ total difficulty score derived by summing up the scores of the first four scales of the $\mathrm{SDQ}^{34}$ measured at age 9 and 11 years.

Paternal involvement was measured by asking fathers to rate their level of agreement-on 3-6-point ordinal scales-with items developed exclusively for the study by the ALSPAC study team and not drawn from an existing scale. We identified and selected 58 statements based on paternal report which reflected direct care and associated household tasks, fathers' attitudes to parenting, relationship with child, and fathers' moods and feelings in the post-partum period at 8 weeks (37 items) and 8 months (21 items) after the birth of the child.

Data on other factors measured after recruitment which, according to the literature ${ }^{35-40}$ were potentially associated with the main outcome and/or exposure were also obtained including parental age, level of education (O-level/Certificate of Secondary Education (CSE)/vocational training, A-level or university degree), parity, depression symptoms measured 8 weeks postnatally on the Edinburgh Postnatal Depression Scale (EPDS), ${ }^{41}$ SES derived from self-reported occupation using the Computer Assisted Structured Coding Tool (CASCOT) and coded into quintiles from 1 (lowest) to 5 (highest), (Warwick Institute for Employment Research, "Computer Assisted Structured Coding Tool (CASCOT).” 2000.), number of hours worked in the current or most recently held job, and child's age and gender.

\section{Analysis}

Exploratory factor analysis (EFA) was performed on the items measuring fathers' direct care and associated 
Figure 1 Sample profile of the children included in the analysis. ALSPAC, Avon Longitudinal Study of Parents and Children; SDQ, Strengths and Difficulties Questionnaire.

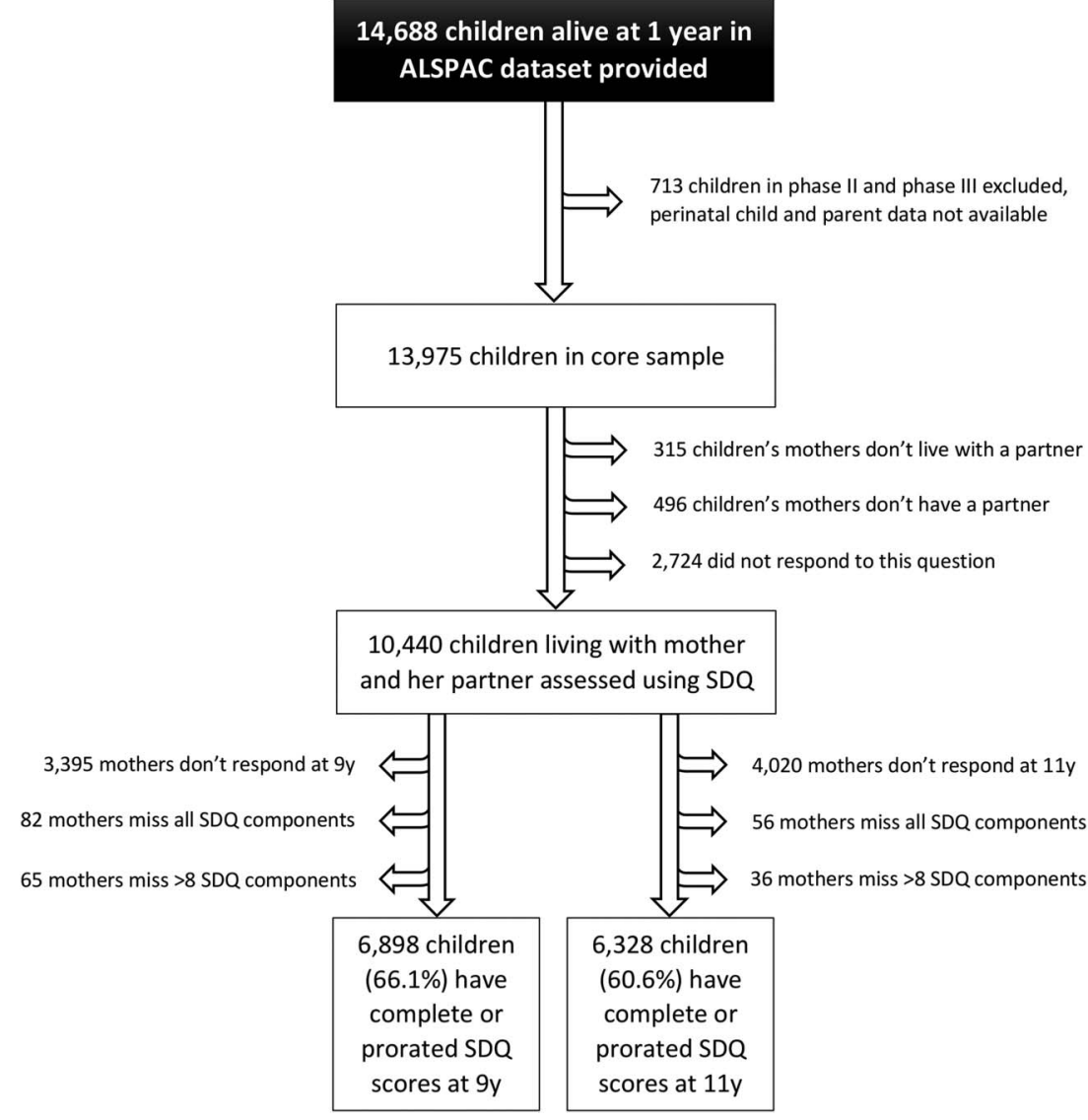

household tasks, attitudes, relationship with child, and moods and feelings in the early months. Factors identified in this analysis were deemed to represent key aspects of paternal involvement. Next, confirmatory factor analysis (CFA) was undertaken to check whether the factor structure identified during EFA was a good fit for the data. To improve the fit of the CFA model items that loaded on more than one factor were removed from further analysis, as were items with low factor loadings $(<0.3)$, because they were deemed to be poor measures of the underlying construct. ${ }^{42}$ Once a well-fitting factor structure was identified, factor scores for each of the identified aspects of paternal involvement were calculated. Factor scores are standard normal estimates of each individual's relative position in the continuum of the latent characteristic being measured. They were calculated as the maximum of the posterior distribution (MAP) of the latent factors given the observed and unobserved responses corresponding to the individual. ${ }^{43}$ Factor scores so derived yield unbiased regression slopes when used as predictors in models. ${ }^{44}$ Labels corresponding to the construct represented by the items underpinning each factor were then attributed to the factor scores to facilitate interpretation of the results.

To explore the association between paternal involvement and behavioural outcomes a two-step procedure was undertaken. First, univariable-ordered logistic regression models of SDQ total difficulties scores on the factor scores and paternal, maternal and child covariates were fitted to identify the factors which were associated with the outcome. Next, all factors found to be independently associated with SDQ score (likelihood ratio $\mathrm{p}$ values $<5 \%$ ) were included in a multivariable model, retaining only those factors for which there was still evidence of association with the outcome even after adjustment. Potential differences in association for boys and girls were explored by fitting and testing interaction terms for gender. Separate models were fitted for SDQ measured at 9 and 11 years.

Missing data were dealt with in three ways. First, the MAP estimation of factor scores allowed for the partial recovery of information contained in unobserved paternal involvement items. Second, missing data in SDQ component items were handled by prorating scale scores for up to two missing responses out of the five items in each scale. ${ }^{34}$ It is a single imputation procedure which replaces an individual's missing item scores with the mean score for the scale to which the missing item belongs. Third, missing values of covariates in the multivariable regression modelling were assumed to be missing completely at random. Multiple imputation was performed to recover the information contained in these missing values, with 10 imputed datasets used to obtain the final estimates.

The proportional odds assumption underpinning the ordered logistic regression models was examined using the Brant test with $\chi^{2} \mathrm{p}$ values $<5 \%$ interpreted as a violation of this assumption. ${ }^{45}$ Data management and 
manipulation were performed using Stata V.13 (StataCorp. "Stata 13." StataCorp LP, College Station, TX: 2013.). Analyses were run in Stata V.13 and MPlus V.7 (Muthén LK, Muthén BO. MPlus 7. Los Angeles, CA: Muthén \& Muthén, 2015).

\section{RESULTS}

The characteristics of the samples at 9 and 11 years were very similar (table 1 ). Overall there were slightly more boys than girls. Fathers were on average aged 31 years and educated to O-level or CSE (examinations completed in the final year of compulsory schooling at age 16 years) or had some vocational (skills) training. They reported working about 45 hours/week in their current or most recent job around the time when the child was 8 months old and had low depression scores on the EPDS. Mothers were on average 2 years younger than the fathers, were educated to a similar level, had slightly higher EPDS scores than fathers, and had one child prior to the one included in the study. Parents tended to be in similar SES categories. Most children had low total difficulties scores, with medians of 6 and 5 at the two respective time points.

There were complete responses to the 58 paternal involvement questions for between 4560 and 5381 children at 8 weeks and 8 months. A total of 45 of the 58 items reflecting paternal involvement were included in the EFA.

Table 1 Characteristics of the parents and children included in the samples at the two time points

\begin{tabular}{|c|c|c|}
\hline & 9 years $(n=6898)$ & 11 years $(n=6328)$ \\
\hline \multicolumn{3}{|l|}{ Fathers } \\
\hline Age in years 18 weeks after birth of child, mean (SD) & $31.27(5.4)$ & $31.30(5.4)$ \\
\hline \multicolumn{3}{|l|}{ Highest level of education, $n(\%)$} \\
\hline O-level, CSE* or vocational & $3021(43.8 \%)$ & $2758(43.6 \%)$ \\
\hline A-level† & $1482(21.5 \%)$ & $1366(21.6 \%)$ \\
\hline University degree & $1048(15.2 \%)$ & $1002(15.8 \%)$ \\
\hline Missing & $1347(19.5 \%)$ & $1202(19.0 \%)$ \\
\hline Hours worked per week, mean (SD) & $44.83(9.8)$ & $44.77(9.9)$ \\
\hline EPDS score, median (IQR) & $3(1-6)$ & $3(1-6)$ \\
\hline \multicolumn{3}{|l|}{ SES $\ddagger$ category, $n(\%)$} \\
\hline 1-lowest & $138(2.0 \%)$ & $122(1.9 \%)$ \\
\hline 2 & $499(7.2 \%)$ & $453(7.2 \%)$ \\
\hline 3 & $2516(36.5 \%)$ & $2297(36.3 \%)$ \\
\hline 4 & $2361(34.2 \%)$ & $2184(34.5 \%)$ \\
\hline 5-highest & $875(12.7 \%)$ & $823(13.0 \%)$ \\
\hline Missing & $509(7.4 \%)$ & $449(7.1 \%)$ \\
\hline \multicolumn{3}{|l|}{ Mothers } \\
\hline Age in years at birth of child, mean (SD) & $29.30(4.4)$ & $29.33(4.4)$ \\
\hline \multicolumn{3}{|l|}{ Highest level of education, $\mathrm{n}(\%)$} \\
\hline O-level, CSE or vocational & $2564(37.2 \%)$ & $2317(36.6 \%)$ \\
\hline A-level & $1665(24.1 \%)$ & $1564(24.7 \%)$ \\
\hline University degree & $1413(20.5 \%)$ & $1329(21.0 \%)$ \\
\hline Missing & $1256(18.2 \%)$ & $1118(17.7 \%)$ \\
\hline Parity, median (IQR) & $1(0-1)$ & $1(0-1)$ \\
\hline EPDS score, median (IQR) & $5(2-8)$ & $5(2-8)$ \\
\hline \multicolumn{3}{|l|}{ SES category, $\mathrm{n}(\%)$} \\
\hline 1-lowest & $86(1.3 \%)$ & $79(1.3 \%)$ \\
\hline 2 & $443(6.4 \%)$ & $417(6.6 \%)$ \\
\hline 3 & $2844(41.2 \%)$ & $2613(41.3 \%)$ \\
\hline 4 & 2099 (30.4\%) & $1926(30.4 \%)$ \\
\hline 5-highest & $441(6.4 \%)$ & $423(6.7 \%)$ \\
\hline Missing & $985(14.3 \%)$ & $870(13.6 \%)$ \\
\hline \multicolumn{3}{|l|}{ Children } \\
\hline Mean age difference in months, mean (SD) & $0.00(5.8)$ & $0.00(5.8)$ \\
\hline \multicolumn{3}{|l|}{ Gender, $n(\%)$} \\
\hline Boys & 3499 (50.7\%) & $3170(50.1 \%)$ \\
\hline Girls & 3399 (49.3\%) & $3158(49.9 \%)$ \\
\hline SDQ total difficulties score, median (IQR) & $6(3-9)$ & $5(3-9)$ \\
\hline \multicolumn{3}{|c|}{$\begin{array}{l}\text { *O-level and CSE were the national exams which students in England sat in their last year of compulsory school education at age } 16 . \\
\text { †A-levels are preuniversity examinations. } \\
\text { fSES is derived from the CASCOT. } \\
\text { CASCOT, Computer Assisted Structured Coding Tool; EPDS, Edinburgh Postnatal Depression Scale; SDQ, Strengths and Difficulties } \\
\text { Questionnaire; SES, socioeconomic status. }\end{array}$} \\
\hline
\end{tabular}


Table 2 Exploratory factor analysis on the indicators of paternal involvement

\begin{tabular}{|c|c|c|c|}
\hline \multirow[b]{2}{*}{ Indicator } & \multicolumn{3}{|c|}{ Rotated loadings* } \\
\hline & Factor 1 & Factor 2 & Factor 3 \\
\hline Helped with shopping since birth & & 0.4891 & \\
\hline Helped with cleaning home since birth & & 0.7112 & \\
\hline Helped with meal preparation since birth & & 0.7013 & \\
\hline Helped with washing up since birth & & 0.6077 & \\
\hline Helped with housework since birth & & 0.7573 & \\
\hline Helped with cooking meals since birth & & 0.6882 & \\
\hline Helped with clothes wash since birth & & 0.5878 & \\
\hline How frequently partner changes nappy per week? & & 0.5178 & \\
\hline How frequently partner bathes child per week? & & 0.4293 & \\
\hline How frequently partner plays with child per week? & 0.4324 & 0.4107 & \\
\hline How frequently partner walks child outside per week? & & 0.4284 & \\
\hline How frequently partner puts child to bed per week? & & 0.4225 & \\
\hline How frequently partner feeds/helps at night per week? & & 0.4294 & \\
\hline Mum excludes partner from childcare & & & 0.7346 \\
\hline Feel confident with child & 0.3857 & & -0.3201 \\
\hline Feel mum does not trust partner with child & & & 0.6817 \\
\hline Happy with the way mum brings up child & 0.3652 & & -0.4507 \\
\hline Happy with the way partner brings up child & 0.5094 & & -0.4468 \\
\hline Making a strong bond with child & 0.6147 & & \\
\hline My stress is a bad influence on child & -0.3728 & & 0.4486 \\
\hline Home is woman's place, no part for me & & -0.3643 & 0.3871 \\
\hline Partner always getting under mum's feet & & & 0.4928 \\
\hline Mum dislikes partner being involved with child & & & 0.7315 \\
\hline Partner guilty for not enjoying child & -0.5480 & & 0.4373 \\
\hline Partner regrets having child & -0.6553 & & \\
\hline Partner regrets lack of experience of children & & & 0.3160 \\
\hline This child has made partner more fulfilled & 0.6465 & & \\
\hline Parenthood has made partner and mum closer & 0.5038 & & \\
\hline Mum no longer gives partner attention & & & 0.5413 \\
\hline Feel hurt by attention mum gives child & & & 0.5760 \\
\hline Partner well prepared for birth and childcare & & & -0.3166 \\
\hline Partner enjoys getting home to see mum and child & 0.6307 & & \\
\hline Enjoy the baby & 0.8294 & & \\
\hline Preferred not to have had baby & -0.5550 & & \\
\hline Feel confident with baby & 0.5776 & & \\
\hline Dislike mess surrounding baby & -0.3707 & & \\
\hline Pleasure watching baby develop & 0.8240 & & \\
\hline Find baby crying unbearable & -0.3836 & & \\
\hline Constantly unsure whether doing right thing & & & 0.3160 \\
\hline Feel should enjoy baby but am not & -0.6869 & & \\
\hline No time to self & -0.4583 & & \\
\hline Baby made feel more fulfilled & 0.7315 & & \\
\hline Feel babies are fun & 0.8185 & & \\
\hline Talking to baby is important & 0.4211 & & \\
\hline Cuddling baby is very important & 0.4612 & & \\
\hline
\end{tabular}

Reasons for exclusion of 13 items were: high uniqueness coefficients of $>0.9$ affecting 8 items; low loadings on the retained factors affecting 1 item; large amounts of missing data-more than 50\%-affecting 3 items; and similarity between 2 items leading to one of them being dropped. Table 2 presents the results of the EFA.

Three factors of paternal involvement, explaining $66.0 \%$ of the total variance in included items, were identified: items in the first factor, explaining $31.4 \%$ of total variance, described fathers' emotional response to the baby and their parenting role; items in the second factor, explaining $17.7 \%$ of total variance, measured fathers' level of engagement in domestic and childcare activities; and items in the third factor, explaining $16.9 \%$ of total variance, characterised fathers' security in their role as a parent and partner. CFA, which excluded crossloading items (since this implies that they poorly discriminate between factors ${ }^{46}$ ), showed this factor 
Table 3 Unadjusted and adjusted proportional ORs for the effect of paternal involvement on SDQ scores at ages 9 and 11 years, with $95 \% \mathrm{Cls}$ and $\mathrm{p}$ values

\begin{tabular}{|c|c|c|c|c|}
\hline \multirow[b]{2}{*}{$\begin{array}{l}\text { Paternal involvement factor } \\
\text { scores }\end{array}$} & \multicolumn{2}{|l|}{9 years } & \multicolumn{2}{|l|}{11 years } \\
\hline & $\begin{array}{l}\text { Unadjusted } \\
{[n=5717]}\end{array}$ & $\begin{array}{l}\text { Adjusted* } \\
{[n=6223]}\end{array}$ & $\begin{array}{l}\text { Unadjusted } \\
{[n=5262]}\end{array}$ & $\begin{array}{l}\text { Adjusted* }^{*} \\
{[n=5500]}\end{array}$ \\
\hline $\begin{array}{l}\text { Factor 1: "emotional response to } \\
\text { baby and parenting" }\end{array}$ & $\begin{array}{l}\text { OR } 0.79 \\
95 \% \mathrm{Cl} 0.73 \text { to } 0.86 \\
p \text { value }<0.001\end{array}$ & $\begin{array}{l}\text { OR } 0.86 \\
95 \% \mathrm{Cl} 0.79 \text { to } 0.94 \\
p \text { value } 0.001\end{array}$ & $\begin{array}{l}\text { OR } 0.81 \\
95 \% \mathrm{Cl} 0.74-0.88 \\
p \text { value }<0.001\end{array}$ & $\begin{array}{l}0.89 \\
95 \% \mathrm{Cl} 0.81-0.98 \\
p \text { value } 0.017\end{array}$ \\
\hline $\begin{array}{l}\text { Factor } 2 \text { : "engagement in domestic } \\
\text { and childcare activities" }\end{array}$ & $\begin{array}{l}\text { OR } 1.01 \\
95 \% \mathrm{Cl} 0.90-1.14 \\
p \text { value } 0.854\end{array}$ & - & $\begin{array}{l}\text { OR } 1.09 \\
95 \% \mathrm{Cl} 0.97-1.24 \\
p \text { value } 0.160\end{array}$ & - \\
\hline $\begin{array}{l}\text { Factor 3: "security in role as parent } \\
\text { and partner" }\end{array}$ & $\begin{array}{l}\text { OR } 0.72 \\
95 \% \mathrm{Cl} 0.66-0.78 \\
p \text { value }<0.001\end{array}$ & $\begin{array}{l}\text { OR } 0.87 \\
95 \% \mathrm{Cl} 0.79-0.96 \\
p \text { value } 0.006\end{array}$ & $\begin{array}{l}\text { OR } 0.72 \\
95 \% \mathrm{Cl} 0.66-0.79 \\
p \text { value } 0.001\end{array}$ & $\begin{array}{l}\text { OR } 0.89 \\
95 \% \text { Cl } 0.81-0.99 \\
p \text { value } 0.034\end{array}$ \\
\hline
\end{tabular}

structure to be an acceptable representation of the correlations between items in the data according to the model's comparative fit index (CFI), Tucker-Lewis index (TLI) and root mean square error of approximation (RMSEA) $(\mathrm{CFI}=0.916$, TLI=0.911, RMSEA=0.065).

Unadjusted ordered logistic regression showed strong evidence that the first and third factor scores were associated with the outcome (table 3). Children of fathers whose responses corresponded to higher factor 1 scores had $21 \%$ and $19 \%$ reductions in proportional odds of higher SDQ total difficulty scores at ages 9 and 11, respectively, and children of fathers whose responses corresponded to higher factor 3 scores had $28 \%$ reduction in proportional odds of higher SDQ total difficulty scores at both times. Other factors were also found to be associated with the outcome. Specifically, higher parental age, level of education and SES category were associated with reduced proportional odds of higher behavioural difficulty scores, while more hours worked per week, higher EPDS scores, child's age and male gender were associated with poorer behavioural outcomes.

Multivariable models adjusting for these potential confounders were fitted, with multiple imputation of missing values of covariates. The adjusted proportional odds of higher behavioural problems scores were $14 \%$ lower at 9 years and $11 \%$ lower at 11 years per unit increase in factor 1 scores and $13 \%$ lower at 9 years and $11 \%$ lower at 11 years per unit increase in factor 3 scores, comparing children of the same age and gender, family size, SES, who were exposed to the same level of parental depression (table 3). There was no evidence of a difference in the effect of paternal involvement in boys versus girls; $p$ values for interaction of child's gender with factor 1 and with factor 3 were 0.907 and 0.864 , respectively, in models of the outcome at 9 years, and 0.189 and 0.918 , respectively, at 11 years. The proportional odds assumption was not violated in these models; Brant test $\mathrm{p}$ values were 0.078 and 0.050 for models on data at 9 years and 0.316 and 0.514 on models at 11 years.

\section{DISCUSSION}

This analysis of data from over 6000 fathers and children in the south-west of England characterised the nature of paternal involvement in early child upbringing and explored its effects on behavioural outcomes in preadolescent children. We found that the children of fathers whom we characterised as having a positive emotional response to parenting and a sense of security in their role as a parent and partner early in the child's life - corresponding to higher scores on factor 1 and factor 3 , respectively-were less likely to exhibit behavioural problems at 9 and 11 years of age. These factors may reflect ways of behaving and interacting that are a marker of favourable parental characteristics and positive parenting in the longer term. Our analyses also show that the amount of paternal involvement with childcare and household tasks such as shopping, cleaning, cooking, and childcare activities was not associated with later child behavioural problems. This may be because provision of more direct childcare by fathers may simply reflect temporary circumstances and needs, for example, the absence of extended family support and type of partner employment.

Our findings are consistent with previous suggestions that paternal involvement may encompass different aspects of how fathers interact with their children and partners, and these aspects potentially differ in terms of how they manifest themselves in father-child interactions, and also in their effects on child outcomes. While paternal involvement is broadly associated with a variety of positive outcomes for children-either directly or indirectly such as through resource-related benefits on health, education and general well-being-previous evidence for whether it contributes to mental health outcomes has not been consistent. For example, paternal presence and involvement in childcare, ${ }^{47}$ and shared activities, supportive behaviour and feelings of affection towards childre ${ }^{48}$ have been shown to be associated with lower likelihood of behavioural problems in 
children aged 3 and 5-18 years, respectively. Similarly, fathers' involvement in childcare has been linked to cognitive outcomes in 2-6-year-olds. ${ }^{49}{ }^{50}$ However, as in this study, others have found little or no evidence of an effect of fathers' involvement in childcare on behavioural outcomes, ${ }^{49-51}$ suggesting that the amount of paternal involvement in these activities may not be as important for this outcome as the type of involvement and attitudes towards parenting. ${ }^{26}$

Although we measured paternal involvement as a multidimensional construct, our approach did not mirror the three defining elements of an involved father - engagement, accessibility and responsibility-originally proposed by Lamb et al in $1985 .{ }^{19}$ We included in our analysis only children whose fathers (or fatherfigures) were present in the early years but who varied in terms of their level of financial contribution to their families, and as such were not able to distinguish between different levels of fathers' financial contributions. However our analysis adjusted for socioeconomic differences between families based on the likely income level of both parents. This may be a better way of dealing with financial contribution in general since it is increasingly common for either or both parents to be breadwinners, and as such fathers making little or no financial contribution to their family would not necessarily imply a of lack of responsibility. Further deviating from the original Lamb-Pleck conceptual framework, our analysis suggests that paternal involvement may extend beyond activities encompassing direct childcare to associated activities and fathers' attitudes towards the child and themselves as parents.

Positive parenting by fathers may contribute to good outcomes in children in a number of ways. Involved fathers may influence children indirectly by being a source of instrumental and emotional support to mothers who provide more of the direct care for children. ${ }^{26}$ The potential positive effect of this on mothers' well-being and parenting strategies ${ }^{52}$ may then lead to better outcomes in children. ${ }^{53}$ There is evidence that fathers' involvement can also alleviate the impact of factors such as maternal depression which are known to increase children's risk of behavioural problems. ${ }^{54}$ Greater paternal involvement may also lead to or be a manifestation of a happy and cohesive family, ${ }^{55}$ and this may bring about better outcomes in children. Social and cultural differences within and across societies may limit the generalisability of these findings.

There are several limitations to this study. The nature of paternal involvement continues to evolve over time, and because this study is based on a cohort which was born 25 years ago there may be a limit to how generalisable its findings are to the present day. This was an analysis of observational data, and although we have adjusted for several factors known to be associated with child behaviour, we cannot rule out the possibility of residual confounding. There were a number of sources of potential bias. For example, child behavioural outcome measures reported by mothers could have been influenced by the mothers' own mental health or their attitudes to their children which in turn could be associated with paternal involvement. ${ }^{56-58}$ However in these data parent-level predictors preceded child-level outcomes by up to a decade, which is likely to have weakened this bias. We used fathers' own reports of their involvement, and this may have further reduced the potential for information bias that may arise with mother-reported measures of paternal involvement. The large sample size, detailed data on fathers' involvement and our rigorous approach to the analysis were also a strength, particularly in exploring the multifaceted nature of paternal involvement. Finally, a number of plausible mechanisms of the association between paternal involvement and child behaviour support the observed associations.

While acknowledging the impact of both parents on children's development and outcomes, there is scope for further research to address some related questions concerning the role of fathers. These include exploring the effect of paternal involvement on other mental health outcomes such as identity, self-esteem, emotional and social development, and how they vary over time. For example, the effect of paternal involvement on child behaviour may become less important over time especially in the adolescent period when peer relationships and other factors such as age and gender start being more influential. This could be explored using growth curve models, but would require further outcome data points.

\section{CONCLUSION}

The findings of this research study suggest that it is psychological and emotional aspects of paternal involvement in a child's infancy that are most powerful in influencing later child behaviour and not the amount of time that fathers are engaged in childcare or domestic tasks in the household. How new fathers see themselves as parents, how they value their role as a parent and how they adjust to this new role, rather than the amount of direct involvement in childcare in this period, appears to be associated with positive behavioural outcomes in children.

Twitter Follow Charles Opondo at @charlesopondo

Acknowledgements The authors would like to thank Ron Gray for his input during the planning of this project. They are extremely grateful to all the families who took part in this study, the midwives for their help in recruiting them, and the whole ALSPAC team, which includes interviewers, computer and laboratory technicians, clerical workers, research scientists, volunteers, managers, receptionists and nurses.

Contributors All authors contributed to the study design. CO conducted the analysis and all authors interpreted the results. CO produced the draft manuscript to which all authors contributed and provided feedback during its development. All authors approved the final version of the manuscript and will serve as guarantors for its contents.

Funding This paper reports on an independent study which was funded by the Policy Research Programme in the Department of Health, England (grant 108/0001). The views expressed are not necessarily those of the Department. 
The UK Medical Research Council and the Wellcome Trust (grant 102215/2/ 13/2), and the University of Bristol provide core support for ALSPAC.

Competing interests None declared.

Ethics approval Ethical approval for the study was obtained from the ALSPAC Ethics and Law Committee and the Local Research Ethics Committees.

Provenance and peer review Not commissioned; externally peer reviewed.

Data sharing statement Data are available from the Avon Longitudinal Study of Parents and Children (ALSPAC) at the University of Bristol for researchers who meet the criteria for access to confidential data. The authors do not own this data, and have signed a legal agreement with the data owners not to share the data publicly. Permission to access the data is granted by the ALSPAC project at the University of Bristol. Information on data access is available at http://www.bristol.ac.uk/alspac/researchers/data-access.

Open Access This is an Open Access article distributed in accordance with the terms of the Creative Commons Attribution (CC BY 4.0) license, which permits others to distribute, remix, adapt and build upon this work, for commercial use, provided the original work is properly cited. See: http:// creativecommons.org/licenses/by/4.0/

\section{REFERENCES}

1. Freitas Wde M, Silva AT, Coelho Ede A, et a/Paternity: social responsibility of man's role as provider. Rev Saúde Pública 2009;43:85-90.

2. Nyström K, Ohrling K. Parenthood experiences during the child's first year: literature review. J Adv Nurs 2004;46:319-30.

3. Office for National Statistics. Women in the Labour Market. Office for National Statistics, London, UK, 2013.

4. Cipollone A, Patacchini E, Vallanti G. Women labor market participation in Europe: novel evidence on trends and shaping factors. IZA J Eur Labor Stud 2014;3:1.

5. Cohany SR, Sok E. Trends in labor force participation of married mothers of infants. Mon Labor Rev 2007:9:9-16.

6. Barclay L, Lupton D. The experiences of new fatherhood: a socio-cultural analysis. J Adv Nurs 1999;29:1013-20.

7. Raby KL, Roisman Gl, Fraley RC, et al. The enduring predictive significance of early maternal sensitivity: social and academic competence through age 32 years. Child Dev 2015;86:695-708.

8. Schneider BH, Atkinson L, Tardif C. Child-parent attachment and children's peer relations: a quantitative review. Dev Psychol 2001;37:86-100.

9. Desforges C, Abouchaar A. The impact of parental involvement, parental support and family education on pupil achievements and adjustment: A literature review. Education; 2003;30:1-110.

10. Durkin K. Developmental social psychology: from infancy to old age. Blackwell, 1995.

11. Flouri E. Fathering and child outcomes. John Wiley and Sons, 2005.

12. Flouri E, Buchanan A. What predicts fathers' involvement with their children? A prospective study of intact families. Br J Dev Psychol 2003;21:81-97.

13. Aldous J, Mulligan GM. Fathers' child care and children's behavior problems: a longitudinal study. J Fam Issues 2002;23:624-47.

14. Raikes HA, Thompson RA. Attachment security and parenting quality predict children's problem-solving, attributions, and loneliness with peers. Attach Hum Dev 2008;10:319-44.

15. Pettit GS, Laird RD, Dodge KA, et al. Antecedents and behaviorproblem outcomes of parental monitoring and psychological control in early adolescence. Child Dev 2001;72:583-98.

16. Plomin R, Price TS, Eley TC, et al. Associations between behaviour problems and verbal and nonverbal cognitive abilities and disabilities in early childhood. J Child Psychol Psychiatry 2002:43:619-33.

17. Gutman LM, Vorhaus J. The impact of pupil behaviour and wellbeing on educational outcomes. London, UK: Institute of Education, 2012

18. Pleck J. Why could father involvement benefit children? Theoretical perspectives. Appl Dev Sci 2007;11:196-202.

19. Lamb ME, Pleck JH, Charnov E, et al. Paternal behavior in humans. Am Zoologist 1985;25:883-94.

20. McLanahan S, Beck AN. Parental relationships in fragile families. Future Child 2010;20:17-37.

21. Carlson MJ, McLanahan SS, Brooks-Gunn J. Coparenting and nonresident fathers' involvement with young children after a nonmarital birth. Demography 2008;45:461-88.
22. Garfield CF, Chung PJ. A qualitative study of early differences in fathers' expectations of their child care responsibilities. Ambul Pediatr 2006;6:215-20.

23. Romirowsky AM, Chronis-Tuscano A. Paternal ADHD symptoms and child conduct problems: is father involvement always beneficial? Child Care Health Dev 2014;40:706-14.

24. Boyce WT, Essex MJ, Alkon A, et al. Early father involvement moderates biobehavioral susceptibility to mental health problems in middle childhood. J Am Acad Child Adolesc Psychiatry 2006;45:1510-20.

25. Black MM, Dubowitz H, Starr RH. African American fathers in low income, urban families: development, behavior, and home environment of their three-year-old children. Child Dev 1999;70:967-78.

26. Lamb ME, ed. How do fathers influence children's development? Let me count the ways. In: The role of the father in child development. John Wiley \& Sons, 2010:1-26.

27. Brunton G, Sutcliffe K, Twamley K, et al. Becoming a Dad: the impact of fathers' involvement on the mental health of children, mothers and fathers: a systematic rapid evidence assessment of Millennium Cohort Study analyses. EPPI Centre, Social Science Research Unit, 2010.

28. Golding J, Pembrey M, Jones R, ALSPAC Study Team. ALSPAC-the Avon Longitudinal Study of Parents and Children. Paediatr Perinat Epidemiol 2001;15:74-87.

29. Golding J. Children of the nineties. A longitudinal study of pregnancy and childhood based on the population of Avon (ALSPAC). West Engl Med J 1990;105:80-2.

30. Fraser A, Macdonald-Wallis C, Tilling K. Cohort profile: the Avon Longitudinal Study of Parents and Children: ALSPAC mothers cohort. Int J Epidemiol 2013;42:97-110.

31. Boyd A, Golding J, Macleod J, et al. Cohort profile: the "children of the 90s'-the index offspring of the Avon Longitudinal Study of Parents and Children. Int J Epidemiol 2013;42:111-27.

32. ALSPAC Study Team. Accessing the resource. 2016. http://www. bris.ac.uk/alspac/researchers/data-access/data-dictionary/ (accessed 18 Jan 2016).

33. Goodman R. The Strengths and Difficulties Questionnaire: a research note. J Child Psychol Psychiatry 1997;38:581-6.

34. Goodman R. SDQ: information for researchers and professionals about Strengths and Difficulties Questionnaires. Youth In Mind, 2000. http://www.sdqinfo.com/py/sdqinfo/c0.py (accessed 8 Feb 2015).

35. Achenbach TM, Edelbrock CS. Behavioral problems and competencies reported by parents of normal and disturbed children aged four through sixteen. Monogr Soc Res Child Dev 1981;46:1.

36. Bradley RH, Corwyn RF. Socioeconomic status and child development. Annu Rev Psychol 2002;53:371-99.

37. Bulanda RE. Paternal involvement with children: the influence of gender ideologies. J Marriage Fam 2004;66:40-5

38. Harris KM, Morgan SP. Fathers, sons, and daughters: differential paternal involvement in parenting. J Marriage Fam 1991;53:531.

39. Harvey E. Short-term and long-term effects of early parental employment on children of the National Longitudinal Survey of Youth. Dev Psychol 1999:35:445-59.

40. Saha S, Barnett AG, Buka SL, et al. Maternal age and paternal age are associated with distinct childhood behavioural outcomes in a general population birth cohort. Schizophr Res 2009;115: $130-5$.

41. Murray L, Carothers AD. The validation of the Edinburgh Post-natal Depression Scale on a community sample. Br J Psychiatry 1990;157:288-0.

42. Costello A, Osborne J. Best practices in exploratory factor analysis: four recommendations for getting the most from your analysis. Pract Assess Res Eval 2005;10:1-9.

43. Asparouhov T, Muthén B. Plausible values for latent variables using Mplus. 2010. http://www.statmodel.com/download/Plausible.pdf (accessed 1 Feb 2016).

44. Skrondal A, Laake P. Regression among factor scores. Psychometrika 2001;66:563-75.

45. Long JS, Freese J. Regression models for categorical dependent variables using Stata. 2nd edn. StataCorp LP, 2006.

46. Pett M, Lackey N. Making sense of factor analysis. Thousand Oaks, CA: Sage Publications, 2003.

47. Dex S, Ward K. Parental care and employment in early childhood: Analysis of the Millenium Cohort Study (MCS) Sweeps 1 and 2. Institute of Education, London, UK, 2007.

48. Amato PR, Rivera F. Paternal involvement and children's behavior problems. J Marriage Fam 1999;61:375-84.

49. del M Huerta C, Adema W, Baxter J, et al. Fathers' leave, fathers' involvement and child development. OECD Publishing, 2013. 
50. Sullivan A, Cara O, Joshi $\mathrm{H}$. The consequences of childhood disadvantage in Northern Ireland at age 5. Institute of Education, London, UK, 2010.

51. Cabrera NJ, Tamis-LeMonda CS, Bradley RH. Fatherhood in the twenty-first century. Child Dev 2000;71:127-36.

52. Feldman R. Maternal versus child risk and the development of parent-child and family relationships in five high-risk populations. Dev Psychopathol 2007;19:293-312.

53. Amato PR. Father-child relations, mother-child relations, and offspring psychological well-being in early adulthood. J Marriage Fam 1994;56:1031-42.

54. Chang JJ, Halpern CT, Kaufman JS. Maternal depressive symptoms, father's involvement, and the trajectories of child problem behaviors in a US national sample. Arch Pediatr Adolesc Med 2007:161:697-703.

55. Aldous J, Mulligan G, Bjarnason T. Fathering over time: what makes the difference? J Marriage Fam 1998;60:809-20.

56. Harmon D, Perry A. Fathers' unaccounted contributions: paternal involvement and maternal stress. Fam Soc 2011;92:176-82.

57. Kalil A, Ziol-Guest KM, Coley RL. Perceptions of father involvement patterns in teenage-mother families: predictors and links to mothers' psychological adjustment. Fam Relat 2005;54:197-211.

58. Hobcraft J, Kiernan K. Predictive factors from age 3 and infancy for poor child outcomes at age 5 relating to children's development, behaviour and health: evidence from the Millennium Cohort Study. York: University of York, 2010. 